\title{
Knowledge for teaching, knowledge about teaching: exploring the links between education research, scholarship of teaching and learning (SOTL) and scholarly teaching
}

\section{Jennifer Case}

\begin{abstract}
The relationship between education research and the scholarship of teaching and learning (SOTL) is still debated, while a distinction has been made between scholarly teaching and SOTL. This study compares and contrasts two programmes of work that took place in a particular 2nd year engineering course, both led by the author. The first programme was an educational research project investigating student learning in the course. The second programme was a period of teaching, leading to some SOTL output. Analysis of the knowledge drawn on in teaching, confirms that good university teaching is not a direct application of research findings but rather draws on a broad and largely tacit practical base of knowledge. The article also offers a deliberation on whether it is productive to maintain the distinction between education research and SOTL.
\end{abstract}

\section{Introduction}

The idea of a 'scholarship of teaching' (later expanded to 'scholarship of teaching and learning', SOTL) arrived on the academic scene in the early 1990s with the publication of Scholarship reconsidered: Priorities of the professoriate, by Ernest Boyer (1990). Its arrival was timely. Boyer had been concerned that the increasing status accorded to research in the academy was at the expense of a focus on teaching, and this concern resonated with the growing academic (also termed education) development movement, which argued for the necessity of improved university teaching to deal with the needs of a massified and increasingly diverse student population (Clegg, 2009). The idea of SOTL grew quickly, within the US but also within other Anglophone contexts, spawned conferences and a journal, and has started to show influence in some university promotion policies (Chalmers, 2010; Vardi and Quin, 2010). In South Africa, the setting for the present study, there is substantial interest in SOTL given the current pressures to improve student 
learning outcomes and a consequent focus on professional development for academics as teachers. However, it needs to be noted that from the outset, there has been a debate on what actually constitutes SOTL and this debate continues to the present. A recent contribution by Kreber concedes that SOTL is still a "contested concept" (2013, p.857). This article therefore starts with an overview of the conceptual work to date in this area.

Boyer had formulated 'scholarship of teaching' as one of the counterpoints he offered to the 'scholarship of discovery', his description of the traditional research valued in the university. In defining SOTL as one of the forms of scholarship (research), it might be assumed that SOTL is a subfield of educational research. On the other hand, Boyer's actual (brief) description of the 'scholarship of teaching' suggests that by this term he had in mind a particular approach to teaching, a scholarly approach.

Acknowledging this potential conceptual confusion, in an influential article Hutchings and Shulman (1999) proposed that a distinction be made between 'scholarship of teaching' and 'scholarly teaching'. To do this they start with a focus on 'excellent teaching', which they argue is the obligation of all academics - engaging students, and facilitating learning. 'Scholarly teaching' they define as a form of teaching which builds on excellent practice but goes beyond this to be informed by current literature, to collect evidence in the classroom, and, on the basis of this, to engage in high level reflection. 'Scholarship of teaching' has three additional characteristics in that it is "public ('community property'), open to critique and evaluation, and in a form that others can build on" (p.13). It focuses inquiry on student learning.

Working with these clear distinctions, Richlin (2001) sees a progressive process which begins with scholarly teaching and all the reflective and deliberative processes which this entails, whereafter the potential exists for the teacher to take this further to develop SOTL:

\footnotetext{
The scholarship of teaching, in my view, builds on the end product of scholarly teaching. Having completed the process to the point of evaluating the results of the teaching intervention, the professor must decide whether or not to proceed with turning the findings into the scholarship of teaching. Clearly, this would depend on the significance of results. The professor may also consider, however, whether the extra effort to write up the material, subject it to another peer review, and disseminate the resulting manuscript would be worth the time required in terms of faculty rewards. (p.61)
} 
SOTL, read in these terms, has a very close relationship to educational research more broadly, and some scholars have sought to clarify this relationship. Crucially, SOTL emerges from the (university) teaching context, and is usually conducted by the teacher. In this regard these debates could potentially be productively informed by the significant literature on practitioner research in the school teaching context (Cochran-Smith and Lytle, 2009; Lunenberg, Ponte and Van de Ven, 2007). With regard to SOTL, established education researchers have sounded cautions around the possibility that university academics with no prior social science or humanities education can quickly move to producing knowledge in a new field (school teachers typically have had significant exposure to the disciplinary field of education), and concerns have been raised about the quality of some SOTL work that has thus far been presented at conferences Brew, 2011; Elton, 2009). Prosser (2008, pp.2, 4) offers a fairly explicit position in this regard, stating that SOTL is "not research in the traditional sense" but rather "evidence based critical reflection on practice to improve practice". Inasmuch as Prosser recognises the value of an 'interplay' between these two activities, he argues for maintaining a clear distinction between SOTL and education research.

Trigwell and Shale (2004, p.534), in considering such a conception of SOTL (as a form of practitioner research) and returning to Boyer's original intentions to promote the status of teaching as an activity in the academy, are concerned that an enterprise that gets academics to focus on SOTL outputs, could be at the expense of an actual focus on (scholarly) teaching:
However, we have argued against a conception of scholarship of teaching that places too great an emphasis on the production of pedagogic knowledge. It potentially displaces teaching practice, and pedagogic resonance, from the apex of a conception of scholarship of teaching to its margins.

Thus they argue for a distinctive approach to SOTL, much along the lines of Prosser - one that does not conflate it with education research, but keeps it squarely focused on classroom concerns. They go on to write further:

\footnotetext{
We see teaching as a scholarly process aimed at making learning possible (Ramsden, 1992). It, therefore, follows that we see the scholarship of teaching as about making transparent, for public scrutiny, how learning has been made possible. (Trigwell and Shale, 2000, p.525)
}

In an attempt to contribute to this debate, the present article takes as a departure point the explicit distinction between scholarly teaching, 
scholarship of teaching and learning (SOTL), and education research outlined above. SOTL, although it has much in common with education research and could be considered by some as a sub-field of this domain, is defined by a form of enquiry that emerges from a particular teaching context, and is usually conducted by the teacher, who may or may not also be an established education researcher. In acknowledging the potential significance of these three distinct activities, this analysis will look to interrogate the forms of knowledge that they both draw on and produce.

The article presents a case study of a course in which I, at two different periods, adopted firstly the role of education researcher (working in conjunction with the course lecturer) and, approximately a decade later, took on the role of teacher in this same course. In the first engagement, as an education researcher ( $\mathrm{PhD}$ student at that point), I had an explicit intention to produce education research on student learning. In the second engagement, as a university teacher, my focus was towards teaching and learning, and the focus of this study is on whether any aspects of scholarly teaching or SOTL could be identified in that work. This case study allows thus for an interesting comparison of education research, SOTL, and scholarly teaching, all conducted by the same person albeit at different points in time, in the same university course context.

\section{Knowledge and teaching}

To take this discussion further, it is important to consider the relationship between knowledge and professional work, with professional work in this instance referring to teaching. Here there is a growing literature mostly emanating from the school context, often with a departure point examining the formal pre-service education of teachers (Ball, 2000). Early work by Lee Shulman $(1986,1987)$ outlined a range of knowledge types that teachers need to be able to draw on in their practice. Clearly, at whatever level, teachers need knowledge of the subjects that they will teach. At a university level, this is often considered the only really important qualification for teaching, one's disciplinary knowledge. Shulman's key contribution was to note that for teaching one requires a reworking of disciplinary knowledge that transforms it into what he termed 'pedagogical content knowledge', an orientation which also includes knowledge around student learning in this disciplinary area. 
For the purposes of this investigation, however, we are more concerned with what might be termed pedagogical knowledge, knowledge around teaching and learning. What knowledge do expert teachers draw on, in addition to their (pedagogical and disciplinary) content knowledge, when planning and when executing teaching? A central influence for conceptualising this kind of professional work has been that of Donald Schön, who highlights the centrality of reflective practice (Schön, 1983), seen also in a conceptualisation of scholarly teaching laid out by Brew (2010). In recent work on the sociology of professional knowledge, Young and Muller (2014) contend that although reflection is no doubt a key orientation in professional work itself, to focus entirely on this activity is to evade the significance of the knowledge bases that professionals recruit to their reflective practice. Thus, although much professional knowledge might be 'tacit', as recognised by Polanyi, it is nonetheless a knowledge base in its fundamental structuring and orientation to the world.

The SOTL literature does offer some recognition of the complexity of accounting for the knowledge that teachers draw on in teaching. Kreber (2013) refers to the Aristotelean typology of 'intellectual virtues' to signal the importance of phronesis (pragmatic and contextual judgement) rather than episteme (scientific knowledge) for SOTL. Here it is worth linking to Flyvbjerg's (2001) contemporary conceptualisation of phronesis, in the context of a broader consideration of social science. Flyvbjerg argues that a phronetic social science is centred on the following three questions:

- Where are we going?

- Is this desirable?

- What should be done?

In summary then, however conceptualised, the literature is clear that teachers draw on a complex range of knowledges, both disciplinary and pedagogical, some tacit and some explicit, to inform their teaching decisions. We can now turn back to the SOTL literature. With the university as a site not only of knowledge acquisition/transmission but also of knowledge production, it is not surprising that the SOTL discussion is centred not only on the knowledge to be drawn on in teaching, but also on knowledge outputs from scholarly activity in the teaching arena (a key definition of SOTL as outlined above). The implicit assumption is that these knowledge outputs will be useful inputs 
that others will draw on in informing their teaching; in fact the definition of scholarly teaching defined earlier gives prominence to the idea that the scholarly university teacher will inform themselves on 'current literature'. There is also an emerging literature on the 'research-teaching nexus' that sees research and teaching as closely intertwined and mutually supportive activities - with an underlying joint concern for the process of learning, whether it be at the student or at the research community level (Bowden and Marton, 1998; Elton, 2001; Healey, 2000; Rowland, 1996). The present article seeks to interrogate these assumptions closely. It needs to be emphasised that drawing on knowledge to inform teaching, and producing knowledge in the context of teaching, are subtly different activities. What knowledge(s) do university lecturers draw on in their teaching? What is the relevance of SOTL or education research outputs in this regard? How is SOTL different to education research?

The research questions directing the present investigation can thus be formulated as follows:

1. Knowledge for teaching: What knowledge(s) do university teachers draw on and how might this relate to teaching that is defined as excellent or scholarly?

2. Knowledge about teaching: What knowledge outputs would constitute scholarship of teaching and learning (SOTL) and how might these differ to education research (or not)? To what extent can these be productively used to inform scholarly teaching?

The case study that informs this investigation focuses on a particular course and my involvement in the different roles of education researcher (termed Phase 1) and teacher (termed Phase 2).

\section{The case study}

This study is located in the context of a second year chemical engineering course at the University of Cape Town in which, at different periods, I was firstly an education researcher, and later the course convenor and lecturer. In 1996 I was appointed to an academic development post in the department with the explicit mandate to focus on improving student learning in the 
programme. My attention fairly quickly gravitated towards this second year course which had a history of relatively high failure rates and was widely regarded as posing particular conceptual challenges to students. I proceeded to formulate my $\mathrm{PhD}$ work in the context of this course, which involved two years (1998-99) of extensive participant observation of class sessions, documentary analysis of student work, and interviews with students and the course lecturers (Case, 2001). Following completion of my PhD I began teaching in the first year of the programme as well as in another second year course and conducted a further piece of educational research with third year students. In 2009 I was given the opportunity to take over the convenership and lecturing in the very second year course in which I had focused my $\mathrm{PhD}$ attentions a decade before. For three years I convened and taught most of the course and thereafter moved into a more minor teaching role in the course. As of 2014 I have no involvement in that course and am teaching mainly in the first year of the programme.

These experiences provided a particular vantage point from which to explore the similarities and differences between conducting education research, performing (scholarly) teaching and engaging in the scholarship of this teaching. In this case study we have the same person as education researcher and teacher, at different points in time, but on essentially the same course (there were no curricular changes to this part of the programme over the period of investigation). It must be noted, however, that the passing of time meant that in many respects it was not 'the same person' doing academic work a year later, nor indeed exactly the same students or course context, given especially the dynamic context of post-apartheid South Africa. Furthermore, the literature on SOTL tends to assume that the person conducting this work has a disciplinary research focus other than education. In this case, education research has been my main research focus, even though the somewhat unusual academic development post has meant that my teaching work has predominantly been in chemical engineering and thus I have some degree of subject specialisation also in that area.

Methodologically, there are always challenges in work that is essentially autoethnographic (Denzin and Lincoln, 2011). To build rigour into the process I analysed the documentary trail that I left from these two periods of work. For the education research and the SOTL this was relatively straightforward; to focus the analysis I selected one journal article from the $\mathrm{PhD}$ (Case and Gunstone, 2002) which I could compare to the journal article from the later SOTL work (Collier-Reed, Case, and Stott, 2013). For the 
teaching work I used the trail of course documentation as well as some university and conference presentations relating to innovations in the course.

The analysis began with tracing an overview of these two periods of work in the different roles of education researcher and then teacher. The analysis proceeded to focus in on the knowledge used for teaching, comparing this with the knowledge outputs in the two phases of work.

\section{Outlining the different roles and associated orientations}

Phase 1: As education researcher on the course

The research project began from a conversation with the course lecturer, who was concerned about the quality of student learning in the course and felt that this was due to insufficient emphasis on the importance of conceptual understanding. She was keen to shift her teaching to increase this emphasis, and, with some input from me, she formulated the following innovations which she began to implement:

- $\quad$ Reduced and more focused content (the course content was reduced by $25 \%$ )

- More interactive teaching (she used various techniques to build student participation into the class)

- Reflective journal tasks (these required students to reflect on their learning and on their conceptual understanding)

- Conceptual assessment items (tests no longer just required calculations)

- $\quad$ One unlimited time test (students could take as long as they liked over one particular test)

I was interested to research how students responded to this new course context, specifically as to whether they shifted their study behaviours towards building the conceptual understanding that the lecturer prioritised. From the student learning literature in higher education I came across the notion of approach to learning, with its broad polarities of deep and surface approaches 
representing whether conceptual understanding was prioritised by the student or not (Ramsden, 1992). From the science education literature, I found the idea of metacognitive development, which represented, I argued, the process of making a shift in approach to learning (Biggs, 1986). I thus formulated a research design working with a small purposively selected group of students to identify the approaches to learning prevalent in the course, and particularly to track any shifts in these approaches, and how these might relate to their perceptions of the course context.

Following a sustained period of interviews over a semester, coupled with an analysis of student work, both deep and surface approaches were identified in this group of eleven students, as well as a third approach, termed a 'procedural approach', where students focused on completing problems that had been assigned in the course as is typical in science or engineering courses. Exploring the ways in which students' perceptions of the evidently time-pressured course context might be related to their choice of approach, those taking a deep approach felt that they should invest time in building understanding in view of long-term benefits - they felt that taking time to understand ultimately saved time. Students using the procedural or surface approaches tended to avoid conceptual tasks as they felt these were too timeconsuming and rather focused attention on meeting the deadlines for course submissions. The results that these students achieved in the course confirmed that the course did actually require students to grasp the conceptual foundations; only those students who ultimately used a deep approach to learning also passed the course. In conclusion, the results of this study were fairly damning for a course structure which retained significant time pressure but required students to change their approach towards a deep approach, if they were not already using it at the outset to the course.

Doing research I was concerned with what was happening in the course, but I channelled these concerns into a project which sought to establish new knowledge, not only for potential use in my context but also for a broader literature on approaches to learning. Inasmuch as it was distressing to interview a student who was failing on the course, as a researcher I was interested to find out what perceptions they held that were related to an approach to learning that was not associated with success on the course. Even though it was clear that students appreciated the opportunity to chat with someone, in the student interview situation I was not able to do much to modify their understanding or approach apart from engaging empathetically and, to some degree, prompting reflection. 


\section{Phase 2: As teacher on the course}

In analysing the foci for my teaching over this period, I began by a comparison with the innovations that I had followed closely in this course during my earlier PhD study. Some of these had been dropped during the period when someone else was teaching the course, and I had reinstated the reduced and focused course content. I also reintroduced the journal tasks. I continued with a relatively interactive teaching style as I had seen exemplified by the course lecturer I had followed during my PhD. I kept the same assessment structure that had been in the course all along; significantly I did not change the time pressured assessment, as had been one of the implicit recommendations of my $\mathrm{PhD}$.

From the document trail, two main innovations can be identified during my period of teaching on the course: designing an integrated project as part of the assessment, and introducing lecture recording (termed here 'lecturecasting', referred to in our journal article as 'podcasting'). These are now described and analysed in terms of the apparent motivations for these developments and the contexts in which they were implemented.

The integrated project followed a general move in engineering to introduce more project work which helps students see the significance of the theoretical material, and also to start to develop engineering skills (Grimson, 2002; Walkington, 2002). A key challenge that I was aware of, given my experience teaching in the first year of the programme, related to students' general struggles with doing work in groups, especially in the context of a culturally diverse class population, coming out of what is still a relatively segregated society with uneven school educational outcomes. To address this challenge, I designed a set of project tasks and arranged the course schedule such that all project work in groups actually took place in class. I made attendance of these sessions compulsory and I monitored and worked closely with groups as they grappled with the work, mediating in instances where groups were not interacting productively.

The lecturecasting was a response to a longstanding concern about students' ability to maximise their learning during lectures. With a large proportion of the class speaking English as a second language, I had been concerned about over reliance on fast verbal delivery and had developed a teaching approach involving extensive 'board work' (now on the tablet) to support this. 
Lecturecasting allowed for a relatively simple recording of the board work with accompanying audio, using Camtasia ${ }^{\circledR}$ software. Students were able to download these recordings as mp4 files from the course website, and could listen to portions or entire lectures at their leisure.

I had a range of methods of obtaining feedback from students, ranging from immediate feedback during informal chats, through to anonymous 'minute papers' where on a weekly basis students gave general feedback on what they were struggling with, as well as the regular mid-semester and end of semester course evaluations (containing fairly standard closed and open-ended items, as well as customised items to gauge the impact of particular innovations).

With regard to the lecturecasting activity I had begun discussions with a colleague who was launching a similar innovation in another engineering course. We decided to construct a more formal enquiry in this context and to this end we recruited a postdoctoral research assistant to conduct focus groups in the class. In the context of the present article this is considered an exemplar of SOTL although at the time we would have most probably described it simply as 'education research', given that both of us had backgrounds in this research area.

Both innovations were well received as shown by detailed course evaluations. For the integrated project I was well aware of negative comments that would usually be made about random group allocation and was pleased to see these decline somewhat and being replaced by comments valuing the opportunity to work with others in class. The lecturecasts were used regularly by just over half the class, and in the focus groups these students expressed that this resource had significantly assisted them in grasping the material in the course.

On completion of my teaching work in this course my reflections in a talk given to university colleagues showed that I still felt challenged by how best to facilitate as many students as possible achieving the necessary engagement with the material - not only in class - but especially also out of class. I was pleased with the levels of engagement with the lecture that I had noted in observations and feedback, but I also noted that students only seemed to work out of class intensively in the few days before a class test. Following the previous lecturer in the course I had introduced a mini-test every second week, but these tests, counting for less marks in the overall assessment, did not seem to stimulate the required ongoing engagement in the course. 
Students were juggling competing demands in multiple courses and my course only got a 'look-in' when a deadline was looming.

\section{Analysis}

Drawing from the detailed data summarised above, the analysis proceeded to respond to the two research questions framing the study. With regard to 'knowledge for teaching', the analysis focused primarily on Phase 2 when I took the role of teacher in the course, and sought to identify the knowledge that I drew on during this period, including the question of to what extent education research (including that which I had conducted in Phase 1) was drawn upon. The question of 'knowledge about teaching' compares the knowledge outputs from these two phases of work, specifically looking to characterise any differences between the education research outputs from Phase 1 and the more SOTL type outputs from Phase 2.

\section{Knowledge for teaching}

When I took over responsibility for teaching on the course, my central concern was to get students learning at a level that was required in the course. As can be seen above, all my actions were explicitly directed towards activities that I thought would 'work' and would make a difference. Many of my teaching decisions here were determined by the logistical constraints in a given course. For example, I had limited class slots and only a regular lecture theatre where I could run the group project, and so I selected groups of three, putting students together so that there was at least one laptop in each group, and arranged them in the lecture theatre so that with ease I could check attendance in each project session. All these decisions were informed by the 'art of the possible'. Lecture recording required me to purchase and develop some facility with the software but was relatively easy to implement, and so I couldn't see any reason not to do so. It did have one constraining influence on my teaching, which was that I had to keep relatively close to the laptop microphone and thus had to change my style for conducting interactive discussions in class.

Teaching was focused on getting learning to happen; I needed to be able to give evidence for my immediate community. Significantly, there was no simple and direct 'application' of research findings in teaching. The teaching 
innovations identified here can certainly be seen to link to contemporary education literature which signals, for example, the value of 'authentic enquiry' (the project work), and the significance of using technology to enhance teaching (the lecturecasting). However, the actual implementation of these innovations was not driven by the research literature. The formulations and the execution appear guided by complex and certainly tacit knowledge derived from experience of teaching, and informed continually by evidence of student learning recruited from the context.

In this instance then of university teaching, it can be seen that while there is some evidence of innovations being informed by broad currents in the literature, it is more important to note how teaching decisions were largely driven by tacit, contextual knowledge, in a framework of reflective practice. In terms of the strict definitions given earlier then, it would be hard to term this 'scholarly teaching' and it would sit more easily in the category 'excellent (or 'good') teaching' given evidence of the success of these innovations within a broader framework of course delivery. I am making this judgement on the evidence that the research literature was not the major driver for the full range of teaching decisions and actions noted over this period.

\section{Knowledge about teaching}

This stage of the analysis aimed to compare the knowledge outputs from these two different periods of engagement with the course, first as an education researcher and then (defined here as) as a teacher engaging in the scholarship of teaching and learning. For the sake of the comparison this analysis looked closely at one journal output as representative of these two activities, an article from my $\mathrm{PhD}$ co-authored with my supervisor (Case and Gunstone, 2002) and an article on the inquiry into pod-casting co-authored with two colleagues (Collier-Reed, Case and Stott, 2013). For easy reference the abstracts of each article are reproduced here:

In this article it is argued that metacognitive development can be viewed as a shift in the approach to learning used by a student. This theoretical position is used to investigate the metacognitive development of a group of students on a course which was aiming to develop deep approaches and conceptual understanding. Considerable diversity was found in the approaches used by students, and also in the degrees to which those not initially using a conceptual (deep) approach were able to develop this approach. In those students initially using an algorithmic approach, one was able to make this transition fairly early on in the course, while others changed to different degrees at later stages. The students using 
information-based approaches did not display any appreciable metacognitive development during this course. The study confirms that the promotion of metacognitive development (i.e. the use of deep approaches) is not easily achieved, and suggests certain aspects of the course environment that are either supportive of or detrimental to metacognitive development. (Case and Gunstone, 2002)

There is a growing literature on the educational benefits of using podcasting of lectures in higher education, but to date little research that interrogates closely its impact on student learning. The present study investigated how students used lecture podcasts produced in two engineering courses at a South African university. The findings confirm much of the growing consensus in the literature. Firstly, a majority of students in the courses elected to use the podcasts. Secondly, the study notes that lecture attendance, in contexts where lectures are seen as beneficial, is not adversely affected. Thirdly, few students use podcasts in the mobile mode but most rather use them as an additional resource in their private study spaces. There is intense use in the build up to tests and examinations, and there is a particular benefit for students who are not first language speakers of the medium of instruction. This study also points to the existence of both deep and surface approaches to engaging with podcasts, with substantial evidence of many students using podcasts as a means towards better understanding. (Collier-Reed, Case and Stott, 2013)

Both articles report on work which had as its origins some pedagogical innovation in the second year chemical engineering course at UCT, with the 2013 article also drawing in data from another course in the faculty. Both articles sought to explore students' perceptions of these innovations and worked with qualitative data collection methods, with the $\mathrm{PhD}$ representing a significantly more sustained process of data collection. Both conceptualised student learning in terms of approaches to learning, with the $\mathrm{PhD}$ linking this also to literature on metacognitive development.

At a deeper analysis these outputs do show some quite notable differences. The 2002 article located itself within a broader literature on students' approaches to learning and thus drove towards findings that were not so much about students' perceptions of an innovation, but which sought to say something potentially broader about student learning in higher education (this noted also in the choice of journal). This is evident even in the abstract to this article which departs from a general position on student learning and proceeds to deliver findings which are represented in fairly general terms. The lecturecasting article maintained a focus on the implementation of this technology in a course and confined its findings to that pedagogical issue, reporting ultimately to a more disciplinary focused journal audience, even though using in conclusion the language of approaches to learning. 


\section{Discussion and conclusion}

In comparing the two phases of this study - the role of education researcher followed by the role of teacher - it can be seen quite clearly how these different roles played out. As a researcher I was focused on building new knowledge and concerned with having something to communicate to a wider research audience. As a teacher I was focused on getting learning to happen and most of my deliberations were focused towards this end. The SOTL-type inquiry into lecture-casting emerged from the teaching context and to some extent validated the impressions I had already formed while teaching. Significantly, there was no simple and direct 'application' of research findings in teaching. The teaching innovations identified here can certainly be seen to link to contemporary education literature which signals, for example, the value of 'authentic enquiry' (the project work), and the significance of using technology to enhance teaching (the lecturecasting). However, the actual implementation of these innovations was not driven by the research literature. The formulations and the execution appear guided by complex and certainly tacit knowledge derived from experience of teaching, and informed continually by evidence of student learning recruited from the context. In terms of the strict definitions offered earlier, we therefore cannot really term this 'scholarly teaching'.

The analysis becomes even more vexing when we compare the knowledge outputs of work that was straightforwardly defined as education research (the $\mathrm{PhD}$ study) and that which for the purposes of this investigation could be considered scholarship of teaching and learning (the lecture-casting article). Both activities delivered journal outputs in the education literature; both conceptualised student learning similarly, and both drew off qualitative data of students perceptions of the course innovation. Subtle differences were evident in the intended audiences for these outputs, with the PhD study clearly aiming for a potentially more generalisable contribution to the student learning literature while the pod-casting study appears to speak more directly to a practitioner audience.

These differences aside though, we ultimately need to decide whether there is value in calling this latter work 'scholarship of teaching and learning' when it could also be described as 'education research'. Adendorff (2011) points to this dilemma in reporting on the work of nine academics at a neighbouring South African university: 


\begin{abstract}
The interest of this study was in the experience of academics that use teaching and learning literature for reflection, dialogue and systematic inquiry into their own teaching practices. Although the respondents conceptualised their work as educational research rather than SoTL, the study was initially framed using the SoTL literature because this literature offered useful descriptions of the range of activities and difficulties associated with academics' efforts. (p.306)
\end{abstract}

In conclusion then this case study brings a useful light to bear on the debates around the meanings of SOTL that were outlined briefly in the opening of this article. If SOTL is to be a scholarship, in other words, a form of research, then it needs to be directed towards the objectives of research. This research can certainly be in the context of teaching and learning challenges, but it will be aiming towards knowledge production. This activity is simply not going to be able to deliver actual changes in the classroom. The activity that is centrally directed towards improving students' learning is good teaching, and even if informed by some of the literature (defined here as 'scholarly'), it will always have its focus on a particular set of challenges in a particular context, and the considerations at hand will go beyond this knowledge. Some of the considerations in the teaching challenges offered up by a particular context are going to require professional knowledge that will not necessarily be of interest to a broader scholarly community.

In summary therefore, this study raises questions about the notion of 'scholarly teaching' as defined in the literature. It has been shown how good university teaching draws on a range of knowledges, many tacit and contextual, and it has been suggested that formal research outputs might not play such a significant role in this regard. If our aim is to facilitate high quality student learning, there might be a significant danger in focusing too much on SOTL outputs at the expense of recognising the complex of deliberations involved in teaching. 


\section{References}

Adendorff, H. 2011. Strangers in a strange land - on becoming scholars of teaching. London Review of Education, 9(3): pp.305-315.

Ball, D.L. 2000. Bridging practices intertwining content and pedagogy in teaching and learning to teach. Journal of Teacher Education, 51(3): pp.241-247.

Biggs, J.B. 1986. Enhancing learning skills: the role of metacognition. In Bowden, J. (Ed.), Student learning: research into practice. Melbourne, Australia: Centre for the Study of Higher Education, University of Melbourne, pp.131-148.

Bowden, J. and Marton, F. 1998. The university of learning. London: Kogan Page.

Boyer, E.L. 1990. Scholarship reconsidered: priorities of the professoriate. Carnegie Foundation for the Advancement for Teaching.

Brew, A. 2010. Transforming academic practice through scholarship. International Journal for Academic Development, 15(2): pp.105-116.

Brew, A. 2011. Higher education research and the scholarship of teaching and learning: the pursuit of excellence. International Journal for the Scholarship of Teaching and Learning, 5(2): pp.1-4.

Case, J.M. 2001. Students' perceptions of context, approaches to learning and metacognitive development in a second year chemical engineering course. Unpublished PhD, Monash University, Melbourne.

Case, J.M. and Gunstone, R.F. 2002. Metacognitive development as a shift in approach to learning: an in-depth study. Studies in Higher Education, 27(4): pp.459-470.

Chalmers, D. 2010. Progress and challenges to the recognition and reward of the Scholarship of Teaching in higher education. Higher Education Research \& Development, 30(1): pp.25-38. 
Clegg, S. 2009. Forms of knowing and academic development practice. Studies in Higher Education, 34(4): pp.403-416.

Cochran-Smith, M. and Lytle, S.L. 2009. Inquiry as stance: practitioner research for the next generation. Teachers College Press.

Collier-Reed, B.I., Case, J.M. and Stott, A. 2013. The influence of podcasting on student learning: a case study across two courses. European Journal of Engineering Education, 38(3): pp.329-339.

Denzin, N.K. and Lincoln, Y.S. 2011. The Sage handbook of qualitative research. Thousand Oaks, CA: Sage.

Elton, L. 2001. Research and teaching: conditions for a positive link. Teaching in Higher Education, 6(1): pp.43-56.

Elton, L. 2009. Continuing professional development in higher education: the role of the scholarship of teaching and learning. Arts and Humanities in Higher Education: An International Journal of Theory, Research and Practice, 8(3): p.12.

Flyvbjerg, B. 2001. Making social science matter. Cambridge: Cambridge University Press.

Grimson, J. 2002. Re-engineering the curriculum for the 21 st century. European Journal of Engineering Education, 27(1): pp.31-37.

Healey, M. 2000. Developing the scholarship of teaching in higher education: a discipline-based approach. Higher Education Research and Development, 19(2): pp.169-189.

Hutchings, P. and Shulman, L.S. 1999. The scholarship of teaching: new elaborations, new developments. Change: The Magazine of Higher Learning, 31(5), pp.10-15.

Kreber, C. 2013. Empowering the scholarship of teaching: an Arendtian and critical perspective. Studies in Higher Education, 38(6): pp.857-869. 
Lunenberg, M., Ponte, P. and Van de Ven, P.-H. 2007. Why shouldn't teachers and teacher educators conduct research on their own practices? An epistemological exploration. European Educational Research Journal, 6(1): pp.13-24.

Prosser, M. 2008. The scholarship of teaching and learning: what is it? A personal view. International Journal for the Scholarship of Teaching and Learning, 2(2): pp.1-4.

Ramsden, P. 1992. Learning to teach in higher education. London: Routledge.

Richlin, L. 2001. Scholarly teaching and the scholarship of teaching. New directions for teaching and learning, 86: pp.57-68.

Rowland, S. 1996. Relationships between teaching and research. Teaching in Higher Education, 1(1): pp.7-20.

Schön, D. 1983. The reflective practitioner. New York: Basic Books.

Shulman, L.S. 1986. Those who understand: knowledge growth in teaching. Educational Researcher, 15(2): pp.4-14.

Shulman, L.S. 1987. Knowledge and teaching: foundations of the new reform. Harvard Educational Review, 57(1): pp.1-23.

Trigwell, K. and Shale, S. 2004. Student learning and the scholarship of university teaching. Studies in Higher Education, 29(4): pp.523-536.

Vardi, I. and Quin, R. 2010. Promotion and the scholarship of teaching and learning. Higher Education Research \& Development, 30(1): pp.39-49.

Walkington, J. 2002. A process for curriculum change in engineering education. European Journal of Engineering Education, 27(2): pp.133-148.

Young, M. and Muller, J. 2014. From the sociology of professions to the sociology of professional knowledge. In Young, M. and Muller, J. (Eds), Knowledge, expertise and the professions. London: Routledge, pp.3-17. 
Jennifer Case

Centre for Research in Engineering Education

Department of Chemical Engineering

University of Cape Town

jenni.case@uct.ac.za 